\title{
Highly Selective and Considerable Subcritical Butane Extraction to Separate Abamectin in Green Tea
}

\author{
Yating Zhang ${ }^{1}$, Lingbiao Gu${ }^{1}$, Fei Wang ${ }^{2}$, Lingjun Kong ${ }^{1}$, Huili Pang ${ }^{1}$ and \\ Guangyong Qin ${ }^{1 *}$ \\ ${ }^{1}$ School of Physics and Engineering, Zhengzhou University, Zhengzhou 450001, CHINA \\ ${ }^{2}$ School of Chemistry and Molecular Engineering, Zhengzhou University, Zhengzhou 450001, CHINA
}

\begin{abstract}
We specially carried out the subcritical butane extraction to separate abamectin from tea leaves. Four parameters, such as extraction temperature, extraction time, number of extraction cycles, and solidliquid ratio were studied and optimized through the response surface methodology with design matrix developed by Box-Behnken. Seventeen experiments with three various factors and three variable levels were employed to investigate the effect of these parameters on the extraction of abamectin. Besides, catechins, theanine, caffeine, and aroma components were determined by both high-performance liquid chromatography and gas chromatography-mass spectrometry to evaluate the tea quality before and after the extraction. The results showed that the extraction temperature was the uppermost parameter compared with others. The optimal extraction conditions selected as follows: extraction temperature, $42^{\circ} \mathrm{C}$; number of extraction cycles and extraction time, 1 and $30 \mathrm{~min}$, respectively; and solid-liquid ratio, 1:10. Based on the above study, the separation efficiency of abamectin was up to $93.95 \%$. It is notable that there has a quite low loss rate, including the negligible damage of aroma components, the bits reduce of catechins within the range of $0.7 \%-13.1 \%$, and a handful lessen of caffeine and theanine of $1.81 \%$ and $2.6 \%$, respectively. The proposed method suggested subcritical butane possesses solubility for lipid-soluble pesticides, and since most of the pesticides are attached to the surfaces of tea, thus the as-applied method was successfully effective to separate abamectin because of the so practical and promising method.
\end{abstract}

Key words: subcritical butane extraction, response surface methodolog, abamectin

\section{Introduction}

Tea, along with coffee and cocoa, belongs to the three leading beverages in the world. Tea leaf contains a unique series of natural chemicals, such as tea polyphenols, alkaloid, vitamins, protein, and amino acid ${ }^{1}$. These nutrient and medical components may help people fight with cancer, decrease cholesterol, resist radiation and ageing, promote digestion, and so on ${ }^{2}$. So far, China has steadily been the largest producer of tea in the world, and it has become the mainspring to drive the global growth of tea production $^{3)}$. Unfortunately, the export decreased in recent years, because of the pesticide residues in tea ${ }^{4)}$. Thus, more attention should be paid to the quality and safety of tea ${ }^{5}$.

Abamectin, a novel and efficient biological pesticide, separated from streptomyces avermitilis, is widely used to treat parasitic worms in vegetables, fruit trees, cottons and flowers $^{6}{ }^{6}$. Moreover, abamectin is also classified as one of the highly toxic compounds by the World Health Organization. So, it has a negative impact on the environment and organisms. Besides, abamectin can be transferred to organisms through the food chain and then affect the health of human beings ${ }^{7)}$.

A variety of reports have been published about the testing techniques of pesticide residues in tea ${ }^{8)}$. However, only few report on the separation or extraction of these residues. Current approaches to separate such materials from plants include hydrostatic pressure ${ }^{9)}$, microbial degradation ${ }^{10)}$, ultraviolet degradation ${ }^{11)}$, ozonation degradation $^{12)}$, and chemical degradation ${ }^{13)}$. For instance, sodium carbonate can facilitate the degradation of organophosphorus pesticides ${ }^{14)}$. A study by Wu and coworkers ${ }^{15)}$ indicated

\footnotetext{
*Correspondence to: Guangyong Qin, School of Physics and Engineering, Zhengzhou University, Zhengzhou 450001, CHINA

E-mail: zyt@ @zu.edu.cn

Accepted February 6, 2017 (received for review December 9, 2016)

Journal of Oleo Science ISSN 1345-8957 print / ISSN 1347-3352 online

http://www.jstage.jst.go.jp/browse/jos/ http://mc.manusriptcentral.com/jjocs
} 
that the degradation of pyrethroid in tea increased when the dose of irradiation was raised. Zhan \& $\operatorname{Tian}^{16)}$ found that the captan in apples decreased gradually along with increasing the ozone concentration, treatment time, and reaction temperature. So the optimal technological conditions of degradation are as follows: the initial concentration of ozone should be $6 \mathrm{mg} / \mathrm{L}, \mathrm{pH} 11$, reaction temperature $40^{\circ} \mathrm{C}$, and reaction time $30 \mathrm{~min}$. However, when considering the low degradation efficiency and limited processing conditions, these methods were not widely acceptance.

Since 1980s, supercritical fluid extraction (SFE) was utilized to remove pesticide residue from plants. While the supercritical fluid of $\mathrm{CO}_{2}$ was used to extract pesticide residue from plants at different pressures and temperatures ${ }^{17)}$. Moreover, accelerated solvent extraction(ASE) was used to rapidly detect the contents of organochlorine and organophosphorus on tea leaves ${ }^{18,19)}$. However, no matter SFE or ASE can cause a certain degree of damage to the plant samples. To make matters worse, both techniques require a high working pressure, in the range of 7-50 $\mathrm{Mpa}^{20,21)}$, which can deal with only small sample quantities, thereby preventing large-scale industrial application. Humbert and co-workers ${ }^{22)}$ coupled ion-exchange resin and activated carbon to remove pesticide residue and insoluble organic chemicals from plants. Despite attaining high removal efficiency, this approach is so complicated that it has strict requirements regarding the sample's shape. It is therefore not suitable for tasks in which the original shape of the tea leaves needs to be retained. Fortunately, the emergence of subcritical fluid extraction technology solved a series of problems. This technique uses a green organic solvent. It is relatively simple and rapid, and demands fewer instrumental devices than any other methods, because it takes the advantages of low pressure $(0.2 \sim 0.6$ $\mathrm{MPa})$ and temperature $\left(0 \sim 60^{\circ} \mathrm{C}\right)$, high extraction efficiency, suitability for loop extraction, ease of operation, low energy consumption, and scalability for large-scale industrial extractions when compared with other extraction techniques. So it has been recognized, applied, and practiced in large-scale industrial productions. Currently, it is mostly used for extracting flavors and fragrances ${ }^{23,24)}$, especially for functional edible oils ${ }^{25)}$, natural pigments ${ }^{26)}$, and medicinal compositions ${ }^{27)}$.

In this study, abamectin was separated by a subcritical fluid with butane as solvent. The extraction conditions were surveyed with a three-variable, three-level experiment designed by Box-Behnken, which was based on the response surface methodology (RSM). The separation efficiency of abamectin were assessed by high-performance liquid chromatography (HPLC) tandem mass spectrometry (LC-MS/MS) analysis. Finally, the catechins, caffeine, theanine, and main aroma components were analyzed by HPLC and GC-MS. The results demonstrated that the subcritical fluid extraction technology was practical and prom- ising for extracting trace amounts of pesticide from nature plants.

\section{Materials and methods 2.1 Sample}

The tea leaves used in this study were picked from the tea plantation. In experimental processes, the working concentration of abamectin (100 g/L, Huozhou Oasis Chemicals Co., LTD., in July 2014) was adjusted to twice the suggested value. Three days after spraying the pesticide on the tea trees, the tea leaves located at the top of the branches were picked and then stir fried, then transferred to our laboratory within the same day at a temperature of $4^{\circ} \mathrm{C}$.

\subsection{Apparatus}

Extractions were performed via a subcritical Fluid Extraction System (CBE-5L, Henan Subcritical Biological Technology Co., Ltd., Anyang, China). Abamectin in green tea was determined through an LC-MS/MS (Agilent1200/ API4000, Santa Clara, California, USA). The chromatographic analysis of tea aroma components was conducted using a GC-MS (Agilent 7890-5795, Santa Clara, California, USA). The dried tea samples were ground successively with a herbal medicine grinder (DJ-04B, Dianjiu Traditional Chinese Medicine Machinery Manufacturing Co. Ltd, China), an ultrasonic cleaner (KH-500DE, Huyueming Scientific Instrument Co. Ltd., China), a rotary evaporator (R-210, Buchi, Switzerland), a high-speed refrigerated centrifuge (3K15, Steinheim, Germany), and a vortex mixer (VX200, Labnet, NJ, USA).

\subsection{Reagent}

Acetonitrile, methanol, acetone, ethyl acetate, butane, hexane, etc., were of chromatographic grade and purchased from J. T. Baker (NJ, USA). Anhydrous magnesium sulfate, sodium chloride, citric acid, and sodium citrate dibasic sesquihydrate were of analytical grade and acquired from the North Reagent Company (Tianjin, China). A salting-out reagent kit (Supelco, PA, USA) was used consisting of $4 \mathrm{~g}$ anhydrous magnesium sulfate, $1 \mathrm{~g}$ sodium chloride, 1 g sodium citrate, and $0.5 \mathrm{~g}$ sodium citrate dibasic. Primarysecondary amine (PSA) sorbent was purchased from Supelco(PA, USA). Water $(18.2 \mathrm{M} \Omega \mathrm{cm}$ ) was purified using Milli-Q system equipment (Billerica, MA, USA).

\subsection{Standard substances}

Abamectin $(\geq 99 \%)$, phenethyl acetate $(\geq 99 \%)$, and isazofos $(\geq 95 \%)$ were purchased from Dr. Ehrenstorfer Company (Germany). Six kinds of catechins, caffeine, and theanine were received from Aladdin Company (Shanghai, China). 


\subsection{Subcritical fluid extraction}

For subcritical fluid extraction, fresh tea leaves (100 g) were placed in a filter bag cautiously to avoid damaging the surface structure or the overall shape. The filter bag was then laid aside in the extraction pot of the subcritical fluid extraction apparatus after adding butane. Subsequently, the subcritical fluid extraction process was initiated by tuning the temperature and pressure. Notably, solvent butane could be recycled inside the system by the compressor during the entire extraction process. When the extraction process completed, the extraction liquid in the extraction pot was injected into the evaporating pot. At the same time, by means of vacuum distillation, we remove the butane solvent from the extracts. Finally, the extracts and the tea leaves were collected and taken out, especially.

\subsection{Experimental design}

RSM is a useful tool for optimizing experimental protocols. It can be effectively evaluate the effects of multiple factors and their interactions on one or more response variables. Firstly, in a single-factor experience, four variable factors were chosen to evaluate the influence of extraction parameters on the separation efficiency of abamectin. These critical variable factors include extraction temperature $\left(15^{\circ} \mathrm{C}, 25^{\circ} \mathrm{C}, 35^{\circ} \mathrm{C}\right.$, and $\left.45^{\circ} \mathrm{C}\right)$, extraction time $(10,20,30$, and $40 \mathrm{~min})$, number of extraction cycles $(1,2$, and 3 ), and solid-liquid ratio (1:5, 1:10, and 1:15). Owing to the taste quality of tea as beverage, the upper temperature was restricted to $45^{\circ} \mathrm{C}$. According to the preliminary results, the solid-liquid ratio had no significant effect on the experimental results. The main reason for this phenomenon was that the volume of extraction solvent was excessive compared with these trace pesticide residues. Hence, the subsequent RSM protocol with three factors, three levels, and seventeen experiments was carried out to study the impacts of extraction temperature, extraction time, and number of extraction cycles on the separation efficiency of abamectin for three cycles.

\subsection{Determination of abamectin}

\subsubsection{Standard solution preparation}

The standard stock solution $(10 \mu \mathrm{g} / \mathrm{mL})$ and internal standard solution $(20 \mu \mathrm{g} / \mathrm{mL})$ were prepared by dissolving abamectin and isazofos standard substance in acetonitrile, respectively. Stock solutions were maintained at $4^{\circ} \mathrm{C}$ in a refrigerator. Intermediate working standard solutions were obtained by serial dilution of standard stock solutions with acetonitrile, isazofosacting as an internal standard. $200 \mu \mathrm{L}$ of intermediate working standard solutions and $200 \mu \mathrm{L}$ of blank tea extraction solution were diluted with $600 \mu \mathrm{L}$ acetonitrile to prepare the working standard solution for reducing the matrix interference. The concentration range for abamectin was $4-200 \mu \mathrm{g} / \mathrm{L}^{28)}$.

\subsubsection{Sample pretreatment}

The extraction procedure consisted of the following five major steps: (1) Crushed tea (2.00 g) and $10 \mathrm{~mL}$ of water mixed together in a 50-mL centrifuge tube, then soaked for 10 min. (2) Then the internal standard solution $(100 \mu \mathrm{L})$ and $10 \mathrm{~mL}$ acetonitrile were added and shook for $2 \mathrm{~min}$ (2000 rpm). (3) When a salting-out reagent kit was introduced into the centrifuge tube, it was immediately vibrated for $2 \mathrm{~min}(2000 \mathrm{rpm}$ ) on the vortex mixer, avoiding the local overheating caused by the reaction of anhydrous magnesium sulfate with water, then centrifuged for $10 \mathrm{~min}$ (1467 g). (4) An extract liquid of $1 \mathrm{~mL}$ was acquired and placed into a $2 \mathrm{~mL}$ centrifuge tube containing $150 \mathrm{mg}$ anhydrous magnesium sulfate, $40 \mathrm{mg}$ PSA adsorbent, and $40 \mathrm{mg}$ C18E adsorbent. The extract liquid was continuously vibrated for $2 \min (2000 \mathrm{rpm})$ and centrifuged for $2 \min (3300 \mathrm{~g})$. (5) The extraction solution $(200 \mu \mathrm{L})$ was drawn into the centrifuge tube, diluted to $1 \mathrm{~mL}$ with acetonitrile, and filtered through a $0.22-\mu \mathrm{m}$ nylon filter prior to the LC-MS/MS analysis $^{29)}$. All tests were performed in triplicate.

2.7.3 Chromatographic conditions

The LC-MS/MS analysis of abamectin residues was done with a C18 column $(150 \mathrm{~mm} \times 2.1 \mathrm{~mm} \times 3 \mu \mathrm{m})$ and mobile phase of $0.1 \%$ formic acid in water/acetonitrile mixture. The condition sets as follows: a column oven temperature of $25^{\circ} \mathrm{C}$, an injection volume of $10 \mu \mathrm{L}$, a detector wavelength of $225 \mathrm{~nm}$, and a flow rate of $0.2 \mathrm{~mL} / \mathrm{min}$.

The binary solvent system consisted of acetonitrile(A) and $0.1 \%$ formic acid in water $(\mathrm{B})$, with a linear gradient. The linear mobile phase gradient started at 90\% B(0-1 $\mathrm{min})$, decreased to $50 \% \mathrm{~B}$, remained at $50 \% \mathrm{~B}(1-5 \mathrm{~min})$, ramped to $40 \% \mathrm{~B}(5-16 \mathrm{~min})$, and ramped back to $90 \% \mathrm{~B}$ (16-25 min), where it was maintained (25-30 min). The chromatographic run time was $30 \mathrm{~min}$ in all. Diafenthiuron was detected at 13-15 min, isazofos at 10-12 min. The MS source conditions were as follows: The compound was ionized in the electrospray ionization (ESI) and operated in positive mode. Atomized gas Traffic was $414 \mathrm{KPa}$. Ionization temperature was $500^{\circ} \mathrm{C}$. Four kinds of gases were Nitrogen. Retention time was $30 \mathrm{~ms}$. Ionizing voltage was $5500 \mathrm{~V}$.

\subsection{Determination of aroma components}

\subsubsection{Sample pretreatment}

Simultaneous distillation-extraction(SDE) was used for extracting the aroma components from tea ${ }^{30)}$. Before the extraction, $10 \mathrm{~g}$ of crushed tea was placed into a $1000 \mathrm{~mL}$ round-bottomed flask (sample flask), which was coupled to one arm of the SDE apparatus, containing $200 \mathrm{~mL}$ boiling deionized water and $10 \mu \mathrm{L}$ of phenethyl acetate as an internal standard $(10 \mathrm{mg} / \mathrm{mL})$. Another $100 \mathrm{~mL}$ round-bottomed flask (solvent flask) containing $40 \mathrm{~mL}$ of tetrachloromethane as the extraction solvent was attached to the other arm of the SDE apparatus. The sample was slightly 
boiled and the tetrachloromethane flask was heated and maintained at $55^{\circ} \mathrm{C}$ using a water bath. Then extraction was performed for approximately $2 \mathrm{~h}$. After dehydration by anhydrous sodium sulfate, the extraction solution was concentrated to $2 \mathrm{~mL}$ using a rotary evaporator and filtered through a $0.22-\mu$ m nylon filter prior to GC-MS analysis ${ }^{31}$.

2.8.2 Chromatographic conditions

The GC-MS system used in this study was Agilent 78905790 with DB-5MS column $(30 \mathrm{~m} \times 0.25 \mathrm{~mm} \times 0.25 \mu \mathrm{m})$. Helium acted as the carrier gas with a constant flow rate of $1 \mathrm{~mL} / \mathrm{min}$. The injector and ion source temperatures were $200^{\circ} \mathrm{C}$ and $250^{\circ} \mathrm{C}$, respectively. The oven temperature was isothermal at $40^{\circ} \mathrm{C}$ for $2 \mathrm{~min}$, increased to $260^{\circ} \mathrm{C}$ at $10^{\circ} \mathrm{C} /$ min, and remained isothermal at $260^{\circ} \mathrm{C}$ for $20 \mathrm{~min}$. The mass spectrometer conditions were as follows: ionization mode, EI; electron energy, $70 \mathrm{eV}$; ion source temperature, $250^{\circ} \mathrm{C}$; quadrupole temperature, $150^{\circ} \mathrm{C}$; mass scan range, 33-500 amu; and solvent delay, $3.0 \mathrm{~min}^{32,33)}$.

The six kinds of catechins, theanine, and caffeine contents were determined using a HPLC along with ISO 145022:2005, ISO/DIS 19563, and ISO 10727: 2002, respectively.

\section{Results and Discussion}

\subsection{Results of chromatographic analysis}

The catechins, theanine and caffeine are the main substances which determine the flavor and color of the tea. Therefore, method validations such as linearity and correlation coefficient $\left(R^{2}\right)$ in chromatographic analysis were performed. Calibration curves were constructed by plotting the peak area $(y)$ versus the corresponding concentration $(x, \mathrm{mg} / \mathrm{kg})$ of abamectin, and six kinds of catechins, theanine, and caffeine, and the correlation coefficient $\left(R^{2}\right)$ of all calibration curves were higher than 0.9921 (Table 1). Based on the obtained linear regression equation from cali- bration curves, the abamectin, the six kinds of catechins, theanine and caffeine content in control sample were calculated.

\subsection{Optimization of subcritical extraction condition}

The tea samples were processed by the subcritical fluid extraction system, and the separation efficiency of abamectin is shown in Table 2. The extraction temperature, extraction time, and number of extraction cycles were chosen as independent variables, and the separation efficiency of abamectin was set as the objective function. The experimental data were employed to get the results of variance analysis (Table 3), establishing an ideal second-order polynomial model (Eq. 1) and plot response surfaces (Fig. 1).

$$
\begin{aligned}
Y(\text { abamectin })= & 4.62+0.75 * A+0.034 * B+0.054 * C+ \\
& 0.11 * A * B+0.073 * A * C+0.11 * B * C+ \\
& 0.51 * A^{2}+0.068 * B^{2}+0.028^{*} C^{2}
\end{aligned}
$$

Where $A$ is the extraction temperature, $B$ is the extraction time, and $C$ is the number of extraction cycles. To test reliability of this model, the determination coefficients $\left(R^{2}\right)$ was calculated and the value was 0.9981 , which indicated good agreement between the experimental and predicted values of bifenthrin extract content. From the results of variance analysis in Table 3, the $F(45.77)$ and $P$ values $(<0.0001)$ revealed that the model was statistically significant. The $F$ (298.07) and $P$ values $(<0.0001)$ for extraction temperature indicated that temperature had the most significant influence on the separation efficiency of abamectin among the three conditions ${ }^{34}$; and the following was the number of extraction cycles; while the extraction time effect negligible $^{35}$. The results indicated the same regulation(extraction temperature on bifenthrin extract content was the most important, the next was extraction time, and the smallest contribution was the number of extraction cycle),

Table 1 Linear regression equation, correlation coefficient of abamectin, and six kinds of catechins, theanine, and caffeine.

\begin{tabular}{cllc}
\hline \multicolumn{1}{c}{ Analytes } & Linear regression equation & $R^{2}$ \\
\hline Abamectin & $y=3.9 \mathrm{E}^{-05} x-0.000701$ & 0.9981 \\
Gallic acid & $y=-13.105 x+72.313$ & 0.9940 \\
(-)-Epigallocatechin & $y=-170.28 x+902.70$ & 0.9926 \\
& Catechin & $y=155.17 x-40.97$ & 0.9963 \\
Six kinds of & $(-)$-Epigallocatechin gallate & $y=956.38 x-9.84$ & 0.9995 \\
catechins & $(-)$-Epicatechin & $y=220.80 x-123.50$ & 0.9928 \\
& $(-)$-Epicatechin gallate & $y=26.590 x-28.09$ & 0.9989 \\
& Caffeine (as internal standard) & $y=118.3 x-54.50$ & 0.9921 \\
& Theanine & $y=211.58 x-210.08$ & 1.0000 \\
& Caffeine & $y=44.24 x-3.26$ & 0.9978 \\
\hline
\end{tabular}

$R^{2}$, correlation coefficient. 
Table 2 Design of Box-Behnken and the response values.

\begin{tabular}{|c|c|c|c|c|c|c|c|c|c|}
\hline \multirow{2}{*}{$\begin{array}{l}\text { Experiment } \\
\text { No. }\end{array}$} & \multirow[b]{2}{*}{ A } & \multirow[b]{2}{*}{$\mathrm{B}$} & \multirow[b]{2}{*}{$\mathrm{C}$} & \multirow{2}{*}{$\begin{array}{c}\text { Temperature } \\
\left({ }^{\circ} \mathrm{C}\right)\end{array}$} & \multirow{2}{*}{$\begin{array}{l}\text { Time } \\
(\min )\end{array}$} & \multirow{2}{*}{$\begin{array}{l}\text { Extraction } \\
\text { cycles }\end{array}$} & \multicolumn{3}{|c|}{ Abamectin } \\
\hline & & & & & & & $\begin{array}{c}\text { Content } \\
(\mu \mathrm{g} / \mathrm{g})\end{array}$ & $\begin{array}{l}\text { Extract content } \\
(\mu \mathrm{g} / \mathrm{g})\end{array}$ & $\begin{array}{c}\text { Separation } \\
\text { efficiency }(\%)\end{array}$ \\
\hline 1 & 0 & 0 & 0 & 30 & 20 & 2 & 0.59 & 4.63 & 88.70 \\
\hline 2 & 1 & 1 & 0 & 45 & 30 & 2 & 0.42 & 4.8 & 91.95 \\
\hline 3 & 1 & 0 & 1 & 45 & 20 & 1 & 0.56 & 4.66 & 89.27 \\
\hline 4 & 0 & 1 & 1 & 30 & 30 & 3 & 1.21 & 4.01 & 76.82 \\
\hline 5 & -1 & 1 & 0 & 15 & 30 & 2 & 2.05 & 3.17 & 60.73 \\
\hline 6 & 0 & 0 & 0 & 30 & 20 & 2 & 0.56 & 4.66 & 89.27 \\
\hline 7 & 0 & 0 & 0 & 30 & 20 & 2 & 0.54 & 4.68 & 89.66 \\
\hline 8 & 0 & 0 & 0 & 30 & 20 & 2 & 0.74 & 4.48 & 85.82 \\
\hline 9 & 0 & -1 & 1 & 30 & 10 & 1 & 0.91 & 4.31 & 82.57 \\
\hline 10 & 1 & -1 & 0 & 45 & 10 & 2 & 0.53 & 4.69 & 89.85 \\
\hline 11 & 1 & -1 & 0 & 15 & 10 & 2 & 1.71 & 3.51 & 67.24 \\
\hline 12 & 0 & 1 & 1 & 30 & 30 & 1 & 0.7 & 4.52 & 86.59 \\
\hline 13 & 0 & -1 & 1 & 30 & 10 & 3 & 0.96 & 4.26 & 81.61 \\
\hline 14 & 0 & 0 & 0 & 30 & 20 & 2 & 0.57 & 4.65 & 89.08 \\
\hline 15 & 1 & 0 & 1 & 15 & 20 & 3 & 2.07 & 3.15 & 60.34 \\
\hline 16 & 1 & 0 & 1 & 45 & 20 & 3 & 0.64 & 4.58 & 87.74 \\
\hline 17 & 1 & 0 & 1 & 15 & 20 & 1 & 2.28 & 2.94 & 56.32 \\
\hline Blank & & & & & & & 5.22 & 5.22 & \\
\hline
\end{tabular}

Table 3 Analysis of variance for the quadratic polynomial mode.

\begin{tabular}{ccccccc}
\hline Source & Sum of squares & $d f$ & Mean square & $F$ value & $P$ value & Significance \\
\hline Model & 6.14 & 9 & 0.68 & 45.77 & $<0.0001$ & $*$ \\
$A$ & 4.44 & 1 & 4.44 & 298.07 & $<0.0001$ & $*$ \\
$B$ & $9.11 \mathrm{E}^{-03}$ & 1 & $9.11 \mathrm{E}^{-03}$ & 0.61 & 0.4598 & \\
$C$ & $2.30 \mathrm{E}^{-02}$ & 1 & $2.30 \mathrm{E}^{-02}$ & 1.55 & 0.253 & \\
$A B$ & 0.051 & 1 & 0.051 & 3.4 & 0.1078 & \\
$A C$ & 0.021 & 1 & 0.021 & 1.41 & 0.2736 & \\
$B C$ & 0.053 & 1 & 0.053 & 3.55 & 0.1015 & \\
$A^{2}$ & 1.1 & 1 & 1.1 & 73.52 & $<0.0001$ & \\
$B^{2}$ & 0.019 & 1 & 0.019 & 1.29 & 0.2938 & \\
$C^{2}$ & $3.20 \mathrm{E}^{-01}$ & 1 & $3.20 \mathrm{E}^{-01}$ & $2.18 \mathrm{E}^{+01}$ & 0.0023 & \\
Residual & 0.1 & 7 & $1.50 \mathrm{E}^{-02}$ & & & \\
Lack of fit & 0.078 & 3 & $2.60 \mathrm{E}^{-02}$ & 4.06 & 0.1048 & Not significant \\
Pure error & $2.60 \mathrm{E}^{-02}$ & 4 & $6.45 \mathrm{E}^{-03}$ & & & \\
Corrected total & 6.24 & 16 & & & & \\
\hline
\end{tabular}

$A$, extraction temperature; $B$, extraction time; $C$, number of extraction cycles.

* Significant at $p \leq 0.01$.

${ }^{\dagger}$ Significant at $p \leq 0.05$. 

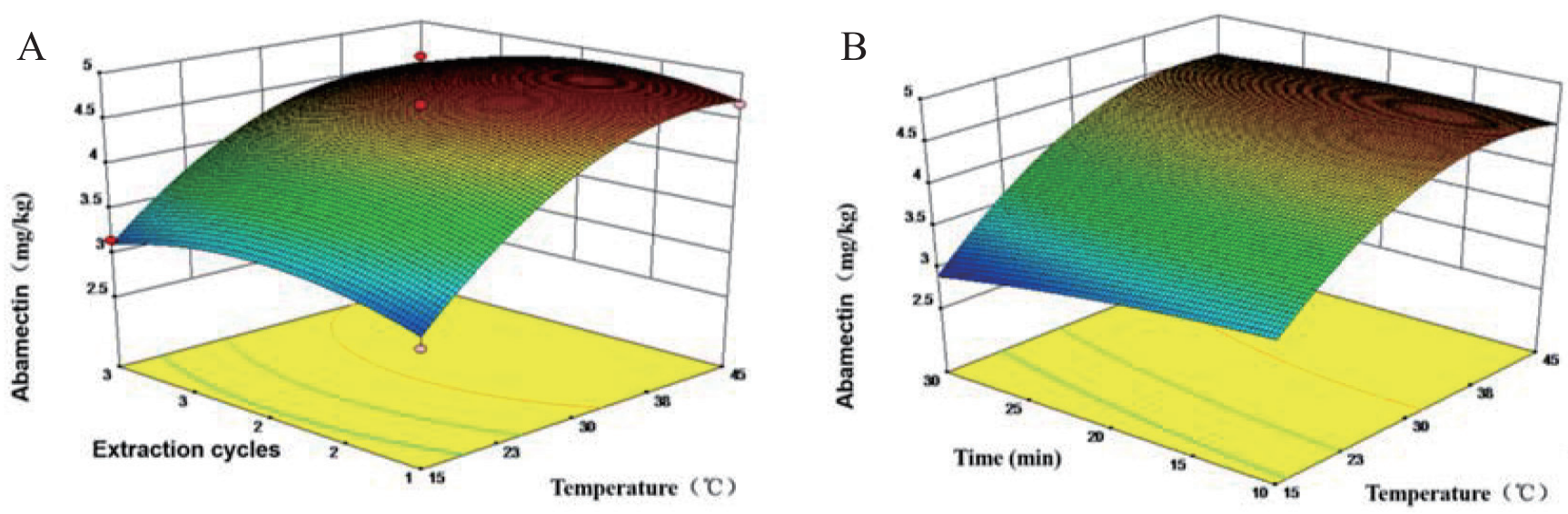

Fig. 1 (A) Effects of temperature and number of extraction cycles on the abamectin content in green tea. (B)Effects of temperature and extract time on the abamectin content in green tea.

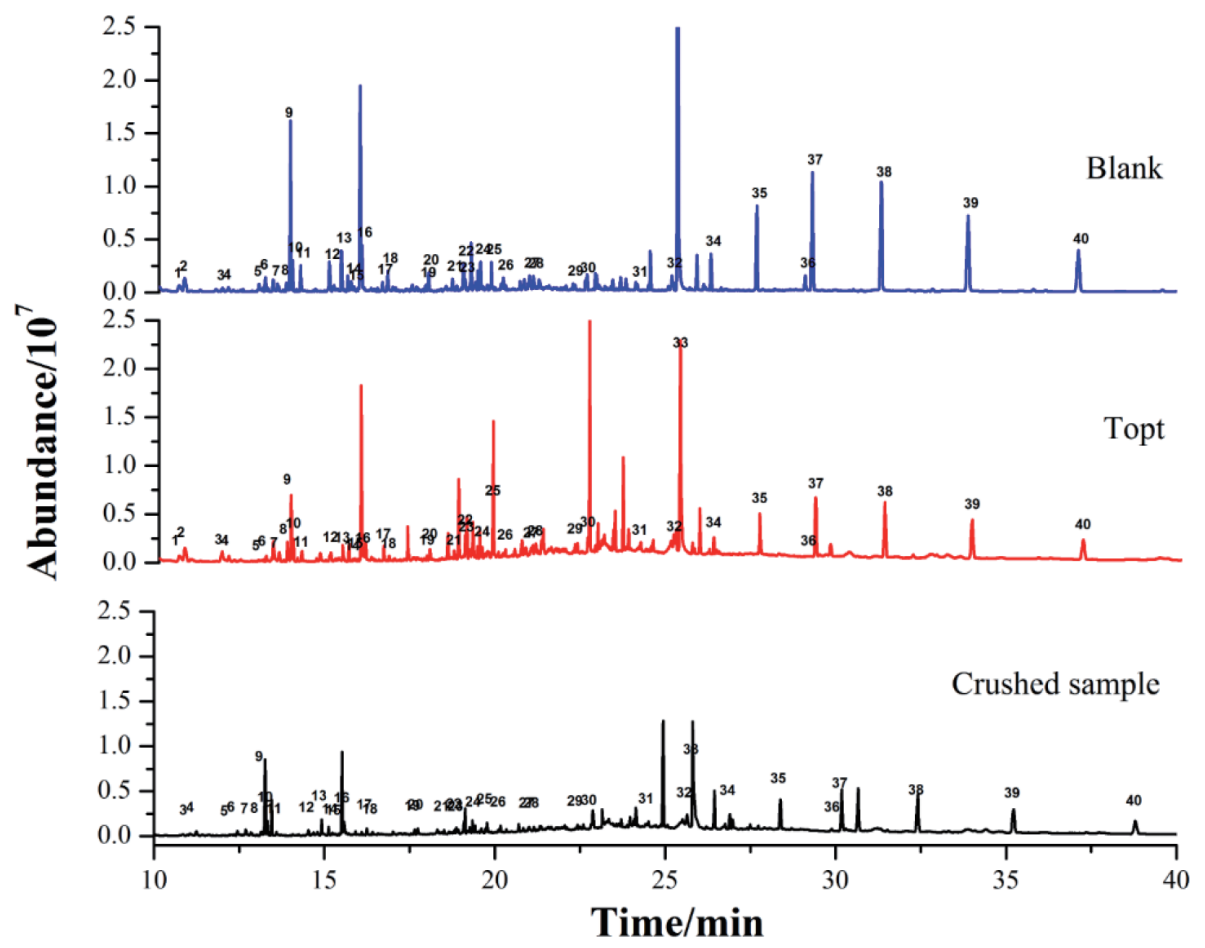

Fig. 2 The total ion chromatograms of aroma components of blank sample, Topt sample and Crushed one.

consistent with the above discussion.

The response surfaces were plotted to study the possible interaction between the variables (Fig. 1) ${ }^{36)}$. As shown in the combined effects in Fig. 1, it can be observed that the response value increased steadily with temperature from $15^{\circ} \mathrm{C}$ to $45^{\circ} \mathrm{C}$ compared with the number of extraction cycles and the extraction time. In addition, the results also showed that when the number of extraction cycles increased in the same temperature, the separation efficiency could be remarkably enhanced and the extraction time had a relatively little effect on the separation efficiency. This phenomenon can be explained from the following two aspects: (1) the pesticide residues can be easily dissolved in butane in a short time because of the trace of abamectin in tea leaf. (2) with the increase in the number of extraction cycles, the solvent osmosis acting on tea leaf will be stronger and more abamectin will be dissolved.

There are three variables including A, B, and C existed extremum in Fig. 2, then the model equation can be simulated based on the Design-Export 8.0.6 and forecasted the optimal condition. The results showed that when A, B and C was $42^{\circ} \mathrm{C}, 1$ and 27.85 min respectively, separation efficiency of bifenthrin reached the maximum $(94.10 \%)$. According to the overall results of the optimization study, the extraction conditions selected as follows: extraction temperature, $42^{\circ} \mathrm{C}$; number of extraction cycles, 1 ; and extrac- 
tion time, $30 \mathrm{~min}$. The three replication experiments in the same condition proved that the average separation efficiency of abamectin was as high as $93.95 \%$, which was close to the theoretical prediction of $94.10 \%$. It can be concluded that the regression equation is reliable for analyzing and predicting the elimination of abamectin by butane.

To make further improvement on the separation efficiency, the effect on Topt(Treated and optimized condition) tea and crushed one was compared. The results were shown in Table 4. The pesticide abamectin can be separated more simple and convenience from ground tea, because of the leaves adequate exposure to butane solvents due to the high specific surface area, which makes the dissolution ratio of abamectin higher. If the appearance of tea is not required in the production process, such as tea bag products, the pesticide similar to abamectin can be removed more sufficiently.

\subsection{Content of catechins, theanine, caffeine, and aroma components}

Six kinds of catechins, theanine, caffeine content, and aroma components were determined, as well as the blank tea sample. Table 5 shows that the rate of loss of catechins is quite low $(9.3 \%)$, and it is not significantly influenced by the extraction temperature, extraction time, and number of extraction cycles. This is mainly because the hydrophilic and lipophilic structure of catechins makes it less soluble in butane ${ }^{37)}$. After the subcritical butane processing, the loss rate of theanine was raised to $2.60 \%$ owing to the low solubility of theanine in butane ${ }^{38)}($ Table 6$)$. And the rate of loss of caffeine was barely $1.81 \%$ (Table 7 ).

The characteristic aroma is an important criterion in the evaluation of the tea quality. In this study, the GC-MS chromatography of the flavor profile of two kinds of tea samples is shown in Fig. 2. In total, 40 volatile compounds were identified and grouped into classes of substances, including 11 alcohols, 12 alkanes, 9 ketones, 3 aldehydes, 3 aromatics, and so on (Table 8). According to the analysis, it can be concluded that subcritical butane extraction has little impact on the content of aroma components from the uncrushed tea. However, the content of aroma components from the ground tea decreased, indicating the tea cells were destroyed and the aroma components adhered to the

Table 4 Separation efficiency of abamectin between Topt tea and crushed one.

\begin{tabular}{cccccccccc}
\hline $\begin{array}{c}\text { Experiment } \\
\text { No. }\end{array}$ & A & B & C & $\begin{array}{c}\text { Temperature } \\
\left({ }^{\circ} \mathrm{C}\right)\end{array}$ & $\begin{array}{c}\text { Time } \\
(\mathrm{min})\end{array}$ & $\begin{array}{c}\text { Extraction } \\
\text { cycles }\end{array}$ & $\begin{array}{c}\text { Content } \\
(\mu \mathrm{g} / \mathrm{g})\end{array}$ & $\begin{array}{c}\text { Extract content } \\
(\mu \mathrm{g} / \mathrm{g})\end{array}$ & $\begin{array}{c}\text { Separation } \\
\text { efficiency }(\%)\end{array}$ \\
\hline Topt & 1 & 1 & 0 & 45 & 30 & 2 & 0.42 & 4.80 & 91.95 \\
Crushed & 1 & 1 & 0 & 45 & 30 & 2 & 0.23 & 4.99 & 95.59 \\
Blank & & & & & & & & 5.22 & \\
\hline
\end{tabular}

Table 5 Catechin content of green tea before and after butane processing.

\begin{tabular}{|c|c|c|c|c|c|c|c|c|c|c|c|c|c|c|}
\hline \multirow{2}{*}{$\begin{array}{c}\text { Sample } \\
\text { (ext temp, ext time, ext cyc) }\end{array}$} & \multicolumn{2}{|c|}{ GA } & \multicolumn{2}{|c|}{ EGC } & \multicolumn{2}{|c|}{$\mathrm{C}$} & \multicolumn{2}{|c|}{ CAF } & \multicolumn{2}{|c|}{ EGCG } & \multicolumn{2}{|c|}{$\mathrm{EC}$} & \multicolumn{2}{|c|}{ ECG } \\
\hline & $\begin{array}{l}\text { Cont } \\
(\%)\end{array}$ & $\begin{array}{c}\text { Decre } \\
(\%)\end{array}$ & $\begin{array}{c}\text { Cont } \\
(\%)\end{array}$ & $\begin{array}{c}\text { Decre } \\
(\%)\end{array}$ & $\begin{array}{l}\text { Cont } \\
(\%)\end{array}$ & $\begin{array}{c}\text { Decre } \\
(\%)\end{array}$ & $\begin{array}{l}\text { Cont } \\
(\%)\end{array}$ & $\begin{array}{l}\text { Decre } \\
(\%)\end{array}$ & $\begin{array}{c}\text { Cont } \\
(\%)\end{array}$ & $\begin{array}{l}\text { Decre } \\
(\%)\end{array}$ & $\begin{array}{l}\text { Cont } \\
(\%)\end{array}$ & $\begin{array}{c}\text { Decre } \\
(\%)\end{array}$ & $\begin{array}{l}\text { Cont } \\
(\%)\end{array}$ & $\begin{array}{c}\text { Decre } \\
(\%)\end{array}$ \\
\hline Blank sample & 0.64 & & 4.52 & & 0.54 & & 3.12 & & 9.15 & & 1.45 & & 1.86 & \\
\hline $\operatorname{Topt}\left(42^{\circ} \mathrm{C}, 30 \mathrm{~min}, 2\right)$ & 0.61 & 4.70 & 4.47 & 1.10 & 0.49 & 9.30 & 3.01 & 3.5 & 8.89 & 2.8 & 1.33 & 8.3 & 1.72 & 7.5 \\
\hline
\end{tabular}

C, catechin; CAF, caffeine; EC, (-)-epicatechin; ECG, EC gallate; EGC, (-)-epigallocatechin; EGCG, EGC gallate; Cont, content (percent of dry leaves); Decre, decrement; ext temp, extraction temperature; ext time, extraction time; ext cycle, extraction cycle.

Table 6 Theanine content of green tea before and after butane processing.

\begin{tabular}{lcc}
\hline Sample (ext temp, ext time, ext cyc) & Content $(\%)$ & Decrement $(\%)$ \\
\hline Blank sample & 1.92 & \\
Topt $\left(42^{\circ} \mathrm{C}, 30 \mathrm{~min}, 2\right)$ & 1.87 & 2.60 \\
\hline
\end{tabular}

Ext temp, extraction temperature; ext time, extraction time; ext cycle, extraction cycle.

Table 7 Caffeine content of green tea before and after butane processing.

\begin{tabular}{lcc}
\hline Sample (ext temp, ext time, ext cyc) & Content $(\%)$ & Decrement $(\%)$ \\
\hline Blank sample & 3.04 & \\
Topt $\left(42^{\circ} \mathrm{C}, 30 \mathrm{~min}, 2\right)$ & 2.985 & 1.81 \\
\hline
\end{tabular}


Table 8 Aroma components of green tea by GC-MS analysis.

\begin{tabular}{|c|c|c|c|c|c|c|c|}
\hline \multirow{2}{*}{ Category } & \multirow{2}{*}{ No. } & \multirow{2}{*}{$\begin{array}{l}\text { Retention } \\
\text { Time }\end{array}$} & \multirow{2}{*}{ Peak } & \multirow{2}{*}{$\begin{array}{l}\text { Molecular } \\
\text { Formula }\end{array}$} & \multicolumn{3}{|c|}{ Relative mass fraction (\%) } \\
\hline & & & & & Blank & Topt & Crushed \\
\hline \multirow{11}{*}{ Alcohol } & 1 & 9.657 & Cyclohexanol & $\mathrm{C}_{6} \mathrm{H}_{12} \mathrm{O}$ & 0.01073 & 0.01089 & 0.01355 \\
\hline & 5 & 12.243 & Benzyl alcohol & $\mathrm{C}_{7} \mathrm{H}_{8} \mathrm{O}$ & 0.00839 & 0.00788 & 0 \\
\hline & 8 & 13.133 & Linalool oxide & $\mathrm{C}_{10} \mathrm{H}_{18} \mathrm{O}_{2}$ & 0.00446 & 0.01525 & 0.00306 \\
\hline & 9 & 13.262 & Linalool & $\mathrm{C}_{10} \mathrm{H}_{18} \mathrm{O}$ & 0.10973 & 0.04377 & 0.10239 \\
\hline & 11 & 13.596 & Phenethyl alcohol & $\mathrm{C}_{8} \mathrm{H}_{10} \mathrm{O}$ & 0.01701 & 0.00791 & 0.00468 \\
\hline & 12 & 14.530 & Epoxylinalol & $\mathrm{C}_{10} \mathrm{H}_{18} \mathrm{O}_{2}$ & 0.02165 & 0.01199 & 0.00896 \\
\hline & 13 & 14.917 & $\alpha$-Terpineol & $\mathrm{C}_{10} \mathrm{H}_{18} \mathrm{O}$ & 0.02691 & 0.01306 & 0.0305 \\
\hline & 14 & 15.237 & 2,6-Octadien-1-ol,3,7-dimethyl-, (2z) & $\mathrm{C}_{10} \mathrm{H}_{18} \mathrm{O}$ & 0.00445 & 0 & 0 \\
\hline & 16 & 15.575 & Geraniol & $\mathrm{C}_{10} \mathrm{H}_{18} \mathrm{O}$ & 0.01808 & 0.00464 & 0.01406 \\
\hline & 25 & 19.777 & Nerolidol & $\mathrm{C}_{15} \mathrm{H}_{26} \mathrm{O}$ & 0.01394 & 0.08613 & 0.00966 \\
\hline & 28 & 21.148 & A-cadinol & $\mathrm{C}_{15} \mathrm{H}_{26} \mathrm{O}$ & 0.00775 & 0.01905 & 0.00486 \\
\hline Total & & & & & 0.24310 & 0.22057 & 0.19172 \\
\hline \multirow{3}{*}{ Aldehydes } & 3 & 11.055 & Benzaldehyde & $\mathrm{C}_{7} \mathrm{H}_{6} \mathrm{O}$ & 0.00457 & 0.01779 & 0.00418 \\
\hline & 6 & 12.447 & Phenylacetaldehyde & $\mathrm{C}_{8} \mathrm{H}_{8} \mathrm{O}$ & 0.00974 & 0.00502 & 0.00867 \\
\hline & 10 & 13.329 & Nonanal & $\mathrm{C}_{9} \mathrm{H}_{18} \mathrm{O}$ & 0.01521 & 0.01515 & 0.01752 \\
\hline Total & & & & & 0.02952 & 0.03796 & 0.03037 \\
\hline \multirow{8}{*}{ Ketone } & 2 & 9.83 & Cyclohexanone & $\mathrm{C}_{6} \mathrm{H}_{10} \mathrm{O}$ & 0.02152 & 0.02432 & 0.02228 \\
\hline & 4 & 11.249 & 2,3-Octadione & $\mathrm{C}_{8} \mathrm{H}_{12} \mathrm{O}$ & 0.00220 & 0.00513 & 0.00978 \\
\hline & 7 & 12.841 & Acetophenone & $\mathrm{C}_{8} \mathrm{H}_{8} \mathrm{O}$ & 0.00882 & 0.00851 & 0.00626 \\
\hline & 15 & 15.32 & Isopulegone & $\mathrm{C}_{10} \mathrm{H}_{16} \mathrm{O}$ & 0.01410 & 0 & 0 \\
\hline & 20 & 17.741 & 3-Methyl-(cis-2-penten-1-yl)-2-cyclopenten-1-one & $\mathrm{C}_{11} \mathrm{H}_{16} \mathrm{O}$ & 0.00994 & 0.00752 & 0.00673 \\
\hline & 21 & 18.515 & 2,6-Di(t-butyl)-4-hydroxy-4-methyl-2,5-cyclohexadien-1-one & $\mathrm{C}_{15} \mathrm{H}_{24} \mathrm{O}_{2}$ & 0.00596 & 0.0065 & 0.00363 \\
\hline & 22 & 18.876 & Beta-ionone & $\mathrm{C}_{13} \mathrm{H}_{20} \mathrm{O}$ & 0.01116 & 0.01143 & 0.00567 \\
\hline & 23 & 18.925 & 4-[2,2,6-Trimethyl-7-oxabicyclo [4.1.0]hept-1-yl]-3-buten-2-one & $\mathrm{C}_{13} \mathrm{H}_{20} \mathrm{O}_{2}$ & 0.00415 & 0 & 0.00377 \\
\hline Total & & & & & 0.07785 & 0.06341 & 0.05812 \\
\hline esters & 37 & 29.961 & Dioctyl adipate & $\mathrm{C}_{22} \mathrm{H}_{42} \mathrm{O}_{4}$ & 0.01407 & 0 & 0 \\
\hline Total & & & & & 0.01407 & 0.00000 & 0.00000 \\
\hline \multirow{12}{*}{$\begin{array}{l}\text { Carbo- } \\
\text { hydrate }\end{array}$} & 19 & 17.644 & Tetradecane & $\mathrm{C}_{14} \mathrm{H}_{30}$ & 0.00340 & 0.00273 & 0.00621 \\
\hline & 26 & 20.167 & Hexadecane & $\mathrm{C}_{16} \mathrm{H}_{34}$ & 0.00460 & 0.00698 & 0.00612 \\
\hline & 29 & 22.423 & Octadecane & $\mathrm{C}_{18} \mathrm{H}_{38}$ & 0.00280 & 0.00812 & 0 \\
\hline & 30 & 22.828 & Anthracene & $\mathrm{C}_{14} \mathrm{H}_{10}$ & 0.00416 & 0.00499 & 0.02839 \\
\hline & 31 & 24.51 & Eicosane & $\mathrm{C}_{20} \mathrm{H}_{42}$ & 0.00247 & 0.01271 & 0 \\
\hline & 32 & 25.635 & Heneicosane & $\mathrm{C}_{21} \mathrm{H}_{44}$ & 0.00835 & 0 & 0 \\
\hline & 34 & 26.9 & Docosane & $\mathrm{C}_{22} \mathrm{H}_{46}$ & 0.02461 & 0.01204 & 0.0234 \\
\hline & 35 & 28.391 & Tricosane & $\mathrm{C}_{23} \mathrm{H}_{48}$ & 0.02461 & 0.01204 & 0.0234 \\
\hline & 37 & 30.196 & Tetracosane & $\mathrm{C}_{24} \mathrm{H}_{50}$ & 0.12403 & 0.06443 & 0.09549 \\
\hline & 38 & 32.432 & Pentacosane & $\mathrm{C}_{25} \mathrm{H}_{52}$ & 0.14130 & 0.06828 & 0.10424 \\
\hline & 39 & 35.246 & Hexacosane & $\mathrm{C}_{26} \mathrm{H}_{54}$ & 0.11879 & 0.06092 & 0.09018 \\
\hline & 40 & 38.821 & 9-Hexylheptadecane & $\mathrm{C}_{23} \mathrm{H}_{48}$ & 0.08040 & 0.03992 & 0 \\
\hline Total & & & & & 0.53952 & 0.29316 & 0.37743 \\
\hline \multirow{5}{*}{ Others } & 17 & 16.246 & Anethole & $\mathrm{C}_{10} \mathrm{H}_{12} \mathrm{O}$ & 0.00600 & 0.009 & 0.009 \\
\hline & 18 & 16.413 & Indole & $\mathrm{C}_{8} \mathrm{H}_{7} \mathrm{~N}$ & 0.01513 & 0.00448 & 0.00413 \\
\hline & 24 & 19.424 & D-cadinene & $\mathrm{C}_{15} \mathrm{H}_{24}$ & 0.01416 & 0.00698 & 0.00785 \\
\hline & 27 & 21.014 & A-copaene & $\mathrm{C}_{15} \mathrm{H}_{24}$ & 0.01387 & 0.01248 & 0.00798 \\
\hline & 33 & 25.825 & Phytol & $\mathrm{C}_{20} \mathrm{H}_{40} \mathrm{O}$ & 0.40355 & 0.22059 & 0.2654 \\
\hline Total & & & & & 0.45271 & 0.25353 & 0.29436 \\
\hline
\end{tabular}


tea surface, thus facilitating the extraction of fat-soluble aroma components easily by the butane extraction process. It is noted that ketone content loss most, which can be interpreted as: the polarity of ketone is more close to butane, solubility of course is the largest based on the similar dissolve mutually theory.

\section{Conclusion}

The separation of abamectin from tea with the subcritical butane extraction technology was surveyed under different conditions. It was found that both the extraction temperature, extraction time, and number of extraction cycle affected the separation efficiency. The optimal factors, including extraction temperature, extraction time, and number of extraction cycles, solid-liquid ratio were selected. Comparing the contents of catechins, theanine, caffeine, and aroma components before and after the subcritical butane extraction, the results revealed that the loss of these components was negligible, suggesting the proposed method was suitable for the effective and selective extraction of abamectin in tea, and it did not influence the quality of tea obviously. Meanwhile, the study demonstrated that subcritical butane has solubility for lipid-soluble pesticides. And since most of the pesticides attach to the surfaces of tea, the subcritical butane has a high effect on wiping them off. In this procedure, more importantly, the quality of tea can still be maintained.

\section{Acknowledgments}

This research was supported by the Foundation of Henan Science and Technology Committee (Grant No. 142300410089).

\section{References}

1) Jiang, Y.; Jiang, X.; Wang, D. Multilayer anchor alignment in AC-E parallel corpora of Chinese tea classics. International Conference on Computational Intelligence and Natural Computing 2(2), 498-501 (2010).

2) Ikeda, I.; Imasato, Y.; Sasaki, E.; Nakayama, M.; Nagao, H.; Takeo, T.; Yayabe, F.; Sugano, M. Tea catechins decrease micellar solubility and intestinal absorption of cholesterol in rats. Biophys. Biochem. Acta 1127, 141-146 (1992).

3) Zhang, G.H.; Yuan, Z.J.; Zhang, C.X.; Yin, K.S.; Tang, M.J.; Guo, H.W.; Fu, J.Y.; Xiao, Q. Detecting deep divergence in seventeen populations of tea geometrid (Ectropis obliqua Prout) in China by COI mtDNA and cross-breeding. Plos One 9 (6), 99373 (2014).

4) Naldi, M.; Fiori, J.; Gotti, R.; Périat, A.; Veuthey, J.L.; Guillarme, D.; Andrisano, V. UHPLC determination of catechins for the quality control of green tea. J. Pharmaceut. Biomed. 88, 307-314 (2014).

5) Huang, Z.; Ying, Z.; Wang, L.; Li, D.; Wang, M.; Yan, H.; Li, Y.; Zhu, S. Simultaneous determination of 103 pesticide residues in tea samples by LC-MS/MS. J. Sep. Sci. 32, 1294-1301 (2009).

6) Payne, L.D.; Hicks, M.B.; Wehner, T.A. Determination of abamectin and/or ivermectin in cattle feces at low parts per billion levels using HPLC with fluorescence detection. J. Agr. Food Chem. 43, 1233-1237(1995).

7) Pal, R.; Sanyal, N.; Das, P.; Pramanik, S.K.; Das, C.; Bhattacharyya, A.; Chowdhury, A. Abamectin in tea and tea liquor under northeastern Indian climatic conditions. B. Environ. Contam. Tox. 76, 126-131 (2006).

8) Cajka, T.; Sandy, C.; Bachanova, V.; Drabova, L.; Kalachova, K.; Pulkrabova, J.; Hajslova, J. Streamlining sample preparation and gas chromatography-tandem mass spectrometry analysis of multiple pesticide residues in tea. Anal. Chim. Acta 743, 51-60(2012).

9) Iizuka, T.; Shimizu, A. Removal of pesticide residue from Brussels sprouts by hydrostatic pressure. Innov. Food Sci. Emerg. 22(4), 70-75(2014).

10) Shelton, D.R.; Doherty, M.A. A model describing pesticide bioavailability and biodegradation in soil. Soil Sci. Soc. Am. J. 61, 1078-1084(1997).

11) Liu, X.; Jian, Z.; Wang, J.; Sun, S. Design and application of ultraviolet degradation equipment for pesticide residue in fruits. Trans. Chin. Soc. Agric. Eng. 27, 355-359 (2011).

12) Chen, J.Y.; Lin, Y.J.; Kuo, W.C. Pesticide residue removal from vegetables by ozonation. J. Food Eng. 114, 404-411 (2013).

13) Hapeman-Somich, C.J. Chemical degradation of pesticide wastes. ACS Sym. Ser. 157-165(2009).

14) Zhang, Y.H.; Xu, D.; Liu, J.Q.; Zhao, X.H. Enhanced degradation of five organophosphorus pesticides in skimmed milk by lactic acid bacteria and its potential relationship with phosphatase production. Food Chem. 164, 173-178(2014).

15) Wu, L.; Chen, C.; Chen, H.; Huang, M.; Du, X.; Xie, Y.; Wang, Y.; Gao, P.; Lei, Q.; Zhou, H.; Luo, L. Influence of irradiation on degradation of pyrethroid pesticide residues in tea and quality of tea. Southwest China J. Agric. Sci. 23, 1121-1124(2010).

16) Zhan, P.; Tian, H.L. Study on degradation of captan residue in apple by ozone. J. Food Sci. 29, 183-186 (2008).

17) Aguilera, A.; Brotons, M.; Rodríguez, M.; Valverde, A. Supercritical fluid extraction of pesticides from a table-ready food composite of plant origin (gazpacho). J. 
Agr. Food Chem. 51, 5616-5621 (2003).

18) Carlo, B.; Chiara, C.; Cristina, I.; Patrizia, R.; Pat, S.; Yariwake, J.H.; Zuin, V.G. SBSE-GC-ECD/FPD in the analysis of pesticide residues in Passiflora alata Dryander herbal teas. J. Agr. Food Chem. 51, 27-31 (2003).

19) Wang, Y.; Zhang, H.X.; Zou, W.L.; Liu, S.B.; Xie, C.M. Determination of organophosphrous pesticides residue in tea using ASE extraction-GPC/SPE purification GC-MS analysis. Food Res. Dev. 3, 37 (2011).

20) Adou, K.; Bontoyan, W.R.; Sweeney, P.J. Multiresidue method for the analysis of pesticide residues in fruits and vegetables by accelerated solvent extraction and capillary gas chromatography. J. Agr. Food Chem. 49, 4153-4160 (2001).

21) Özkal, S.; Yener, M.; Bayındırlı, L. Mass transfer modeling of apricot kernel oil extraction with supercritical carbon dioxide. J. Supercrit. Fluid 35, 119-127 (2005).

22) Humbert, H.; Gallard, H.; Suty, H.; Croué, J.P. Natural organic matter (NOM) and pesticides removal using a combination of ion exchange resin and powdered activated carbon (PAC). Water Res. 42, 1635-1643 (2008).

23) Khuwijitjaru, P.; Sayputikasikorn, N.; Samuhasaneetoo, S.; Penroj, P.; Siriwongwilaichat, P.; Adachi, S. Subcritical water extraction of flavoring and phenolic compounds from cinnamon bark (Cinnamomum zeylanicum). J. Oleo Sci. 61, 349-355(2012).

24) Qi, K.; Wang, R. Production safety of oil extraction with $4 \sim$ \# solvent and its product safety. China Oils and Fats 32 (7), 12-14(2007).

25) Shi, Y.; Ma, Y.; Zhang, R.; Ma, H.; Liu, B. Preparation and characterization of foxtail millet bran oil using subcritical propane and supercritical carbon dioxide extraction. J. Food Sci. Tech. 52, 3099-3104(2015).

26) Chiou, T.Y.; Neoh, T.L.; Kobayashi, T.; Adachi, S. Extraction of defatted rice bran with subcritical aqueous acetone. Biosci. Biotechnol. Biochem. 76, 1535-1539 (2012).

27) Adil, İ.H.; Yener, M.E.; Bayındırlı, A. Extraction of total phenolics of sour cherry pomace by high pressure solvent and subcritical fluid and determination of the antioxidant activities of the extracts. Sep. Sci. Technol. 43, 1091-1110(2008).
28) Yang, F.; Bian, Z.; Tang, G. Simultaneous determination of 6 antiseptics in tobacco with LC-MS/MS method. Tobacco Sci. Tech. 45(11), 45-50(2012).

29) Chen, X.; Bian, Z.; Tang, G.; Hu, Q. Determination of 132 pesticide residues in tobacco by gas chromatography-tandem mass spectrometry. Chin. J. Chromatogr. 30, 1043-1055 (2012).

30) Robin, J.; Rikki, S.; Shailja, G.; Babu, G.D.K.; Manisha, K.; Ashu, G. Characterization of volatile components of tea flowers (Camellia sinensis) growing in Kangra by GC/MS. Nat. Prod. Commun. 6, 1155-1158(2011).

31) Sun, Y.; Chen, Q.; Guo, W. Analysis of aromatic compositions in Longjing Teas. J. Zhejiang Univ. 40(2), 186-190 (2013).

32) Wang, D.; Gan, X.; Liang, Z.; Yang, X. Analysis on aroma compositions of tea by SPME and SDE. Southwest China J. Agric. Sci. 1, 028 (2013).

33) Wang, T.; Zhao, M.; He, B.; Huo, X.; Xu, X.; Xu, Z.; Zhuo, H.; Xie, J.; Ma, Y.; Hu, J. Analysis of volatile and semi-volatile components in Chrysanthemum morifolium Ramat absolute prepared by subcritical extraction technology and its application to cigarette flavoring. Analysis 7, 46-52 (2014).

34) Sarkar, J.; Bhattacharyya, S.; Gopal, M.R. Natural refrigerant-based subcritical and transcritical cycles for high temperature heating. Int. J. Refrig. 30, 3-10 (2007).

35) Chen, W.W.; Jiang, J.X.; Jia, Z.B.; Sun, Z.F.; Hu, Z. Optimization of extracting pigment from green tea by central composite design process. Food Sci. Tech. 7, 069 (2008).

36) Adil, İ.H.; Cetin, H.I.; Yener, M.E.; Bayındırlı, A. Subcritical (carbon dioxide + ethanol) extraction of polyphenols from apple and peach pomaces, and determination of the antioxidant activities of the extracts. $J$. Supercrit. Fluid 43, 55-63(2007).

37) Zhu, Q.Y.; Zhang, A.; Tang, D.; Huang, Y.; Chen, Z.Y. Stability of green tea catechins. J. Agr. Food Chem. 45, 4624-4628 (1997).

38) Sugiyama, T.; Sadzuka, Y. Theanine and glutamate transporter inhibitors enhance the antitumor efficacy of chemotherapeutic agents. Biochem. Biophys. Acta 1653, 47-59(2003). 